\title{
On the laws of attraction at cocktail parties: Babble noise influcences the production of number agreement
}

\author{
Short title: Babble noise influcence on agreement \\ PREPRINT: PLEASE DO NOT CITE
}

\author{
Mirko Hanke, Cornelia Hamann, and Esther Ruigendijk \\ School of Linguistics and Cultural Studies, University of Oldenburg, \\ 26111 Oldenburg, Germany
}

This is an Author's Original Manuscript of an article whose final and definitive form, the Version of Record, has been published in Language and Cognitive Processes iFirst 2012, copyright Taylor \& Francis, available online at: http://www.tandfonline.com/10.1080/01690965.2012.696664

Our study tested the effect of external distractor noise on the generation of subject-verb agreement in spoken language, by eliciting agreement attraction errors. We modelled noisy environments with three different speech-free sounds with spectral, or both spectral and intensity modulation characteristics of speech. In silence and unmodulated noise we replicated a plural mismatch effect, where a plural local noun attracts agreement away from a singular marked head noun. Under modulated noise the error patterns changed, and the amount of errors increased in all cases where the head noun of the preamble was marked for plural. Our interpretation is that external noise creates a secondary task load which exerts an influence on the grammatical encoding stage of sentence formulation, depending on acoustic characteristics of the noise. The additional load leads to a slowing down of processing and difficulty to retrieve the correct number information of the head noun when trying to access an inflected verb form. Subjects overcome this difficulty by resorting to default singular marking on the verb. We discuss the results in the light of different mechanisms that have been proposed in psycholinguistic work for the computation of agreement, and we evaluate a possible link to theoretical claims about the origin of the so-called irrelevant sound effect as a competition for processing time on a mechanism establishing or maintaining serial order relations between objects in working memory.

\footnotetext{
${ }^{*}$ Corresponding author:

Email mh@mirkohanke.de
} 


\section{Acknowledgments}

The authors would like to thank Hendrikje Ziemann for her valueable help in running the experiments, as well as the large number of students and staff members who participated voluntarily in the online questionnaire for the material pretest.

The research reported in this paper was funded by the DFG German Research Foundation, grant HA 2335/2-1 awarded to the second author.

\section{Introduction}

One of the fascinating aspects about speaking is that we do it all the time (certainly, some more so than others), and seemingly without much effort.

The task of using language in noise has increasingly come to the attention of psycholinguists. We speak and comprehend under various different circumstances: Imagine a large city, with cars, buses, trams, people screaming, pedestrians talking over the noise to others next to them or on the phone. Now imagine the typical psychological or (psycho-)linguistic department and its laboratory setting: carpet on the floor to silence steps, professional atmosphere, hushed voices, and sometimes even sound-attenuated rooms in which experimental subjects are made to speak, or listen to language. Admittedly, these two examples form a rather extreme opposition, but it should be clear from these imagined settings that while our ability to speak and comprehend language has evolved to function under very different external settings, the presence of external noise imposes the feeling of greater effort in both speaking and comprehending. The question now is what effect noise might have on the speaking process at a cognitive level, in particular during the formulation stage, which is largely assumed to inform a highly modular, automatic process.

The bread-and-butter work of psycholinguists investigating language production very often involves the empirical testing of intra-individual differences in processing, in the simplest case by eliciting stimulus material that differs along one or more linguistic parameters, for instance in order to establish under which (linguistic) conditions processing becomes difficult or even fails. In addition to these linguistic differences, studies using so-called dual-task paradigms create experimental situations in which the comprehension or production process is observed while a secondary task has to be performed (e. g. Oomen \& Postma, 2002; Bock, Dell, Garnsey, Kramer, \& Kubose, 2007). The general logic of experiments in dual-task paradigms is that cognitive (sub-)processes can be influenced or impeded by concurrent processes that compete for shared processing resources (cf. e. g. Ferreira \& Pashler, 2002). Basically, the question this kind of experiment tries to answer is whether and/or to what extent human language processing is subject to disturbance by other tasks. While we initially stated that people can speak all the time and without much apparent effort, there are situations under which speaking can get observably difficult because we are occupied otherwise, or because adverse environmental conditions impose difficulties on the speaking process, like in the case of potentially distracting noise created by other speakers.

In his information processing theory of speaking, Levelt (1989) adresses the question of cognitive resources that might be involved in speaking. According to his account, an attentionally guided process like message generation (conceptualisation) demands resources and is relatively slow. Further steps in the process of speaking, notably the grammatical 
encoding stage during formulation, are however conceived of as largely automatic and, crucially, are assumed to have dedicated processing capacity at their disposal (Levelt, 1989: 20; also see Caplan \& Waters, 1999 and Fodor, 1983).

This rather strong claim that the formulation stage operates automatically and without sharing processing resources with other cognitive functions has been called into question by other authors. For instance, the study by Ferreira and Pashler (2002) established effects of a dual-task load on some of the stages of lexical selection. In two experiments carried out by Oomen and Postma (2002), the number of errors detected in two monitoring tasks was reduced when a secondary task load was present. A car simulator study by Bock et al. (2007) has shown that both comprehending and producing language influences driving performance. Fayol, Largy, and Lemaire (1994) found a higher number of agreement errors in written reproduction of memorised sentences when subjects had to perform a concurrent task, like counting or maintaining unrelated items in memory. Finally, data by Hartsuiker and Barkhuysen (2006) has shown both an effect of individual differences in working memory and of concurrent memory load during the production of subject-verb agreement in Dutch. Taken together, the different studies indicate that automatic processing on the formulation stage, including grammatical encoding, might be more a matter of degree, rather than an all-or-nothing property, and that formulation is not entirely 'resource-free' (cf. Hartsuiker \& Barkhuysen, 2006) i. e. makes use of shared (verbal) working memory resources to some extent.

In the current study we follow this line of research and try to establish whether external distractors, in our case different speech-free noise signals exert an influence on speaking. Or, in other words, we want to test whether the sheer presence of noise can establish a dual-task load that interferes with procedures implied in language production. We are particularly interested in the grammatical encoding stage (Levelt, 1989; Bock \& Levelt, 1994), during which grammatical relations are established and constituent structure is created, a processing stage which is usually assumed to proceed in a largely automatic, 'modular' fashion (cf. Levelt, 1989; but see Garrod \& Pickering, 2007 for discussion). As a testing case, we will take a closer look at the production of agreement between subject and verb and examine the influence of external noise on the amount of agreement errors.

\section{Capacity, resources, and cognitive modularity}

The assumption that some cognitive processes are bound by capacity limits plays an important role in both the discussion about dual-task interference, as well as in investigations into the processing mechanisms underlying language production and perception. The argument is sometimes supported with the observation that humans can keep only a limited amount of information in short term memory. ${ }^{1}$ In order to frame the debate conceptually, it is assumed that processing requires some sort of resource in terms of 'energy', 'time' or (storage/buffer) 'space' (see Salthouse, 1988; Rummer, Mohr, \& Zimmer, 1998).

In the cognitive sciences, this question is tightly linked to the concept of working memory, a system or ability that allows us to retrieve, manipulate and maintain information (Baddeley, 1986, 2003; Nairne, 1990). Limitations of working memory are regularly used as

\footnotetext{
${ }^{1}$ This point is often garnished with the 'magic number' of 7 plus/minus 2 which had been suggested by Miller (1956) as the amount of 'chunks' humans can keep in immediate memory, but see Cowan (2001) or McElree (2001) for evidence that this number may be considerably smaller.
} 
an explanatory construct for individual differences in cognitive performance across domains, including linguistic performance (Salthouse, 1988; Just \& Carpenter, 1992).

However, the concept of working memory is to this date subject of ongoing discussion about both its general architecture, as well as how to measure its capacity. Particularly in the context of research about individual differences, it presents an undeniably challenging task to establish a truly causal link between measures for working memory and measures on other tasks, given the merely correlational nature of the relationship (Conway et al., 2005: 778). In their review of the psychometric properties of some working memory span task, Conway et al. (2005) maintain that the span tasks they investigated clearly reflected 'real' interindividual capacity differences for non-automatic, attentional tasks, while "they do not predict performance on tasks that appear to reflect relatively automatic processing" (p. 778).

The difference between automatic and controlled processing has sparked an important theoretical debate within psycholinguistics, centering on the question whether we should assume a special component of working memory or special 'resources' for (automatic) language processing. If assumed, such a dedicated component is usually referred to as verbal working memory (VWM). The proposal of a VWM model by Just and Carpenter (1992) has been followed by a debate whether (and if so, how) this component should be further subdivided into smaller resources for different linguistic processing steps (e. g. Waters \& Caplan, 1996; Caplan \& Waters, 1999) - or whether a symbolic processing architecture is a probable concept at all (cf. e. g. MacDonald \& Christiansen, 2002).

Just and Carpenter (1992) assume a unitary, energetic processing resource, which is debited more or less strongly by different processing steps. ${ }^{2}$ The authors maintain that their model provides an explanation for the apparent modularity of syntactic processing which is according to the authors not based on an architectural separation between 'encapsulated' modules, but rather because resource limitations constrain possible interactions between syntactic and what they call "pragmatic" processing.

This architectural conception has been contested by Waters and Caplan (1996), based on a range of neuropsychological evidence (also see Caplan \& Waters, 1999; Waters \& Caplan, 2003) and due to concerns about the validity of the tool proposed by Just and Carpenter (1992) to measure individual differences in working memory span (reading span task, Daneman \& Carpenter, 1980, see also Conway et al., 2005 and Garrod \& Pickering, 2007 for discussion). Instead, Waters and Caplan (1996) suggest a more differentiated verbal working memory, which consists of at least two different kinds of resources for verbally mediated tasks. One of these pertains to unconscious, automatic and obligatory linguistic processing, including acoustic, phonological, syntactic, semantic and pragmatic processing. A different set of resources is required for "conscious, controlled, and verbally mediated processes, such as the deliberate search through semantic memory for a piece of information, explicit reasoning, and other tasks (...)" (Waters \& Caplan, 1996, p. 770). Caplan and Waters (1999) further claim that the apparent automaticity or constraint-free working of core linguistic processes originates in the high domain-specificity of these processes,

\footnotetext{
${ }^{2}$ Note that the concept of verbal working memory, as for instance explicated by Just and Carpenter (1992) cannot be identified with the phonological loop component of the model by Baddeley (1986); rather, Just and Carpenter (1992) state that their conception of a 'working memory for language' "corresponds approximately to the part of the central executive in Baddeley's theory that deals with language comprehension." (p. 123, emphasis added)
} 
with relatively few concurrent tasks competing for space or time on underlying cognitive procedures. This might be different for what the authors call "post-interpretive" processes, including attentional, conscious reasoning.

The view of cognitive modularity as the result of domain-specificity of individual processes has also been advocated by Barrett and Kurzban (2006), and is implied in a number of current models of (general) working memory (see for instance Berti, 2010 for a recent review). With respect to verbal working memory, Rummer et al. (1998) argue for a mechanistic explanation of processing constraints by formulating explicit hypotheses about competition for time and/or space in the execution of basic procedures, which in combination make up complex cognitive processes or functions.

This conception of working memory as the combination of a number of individual processes leads us to make the following assumptions: First, in cases where a secondary task load has a detrimental effect on language processing, the secondary task makes use of resources, that is it employs basic procedures, which are also used for the language-related task, and competition ensues. Secondly, when we observe performance on a linguistic task correlate with a measure of verbal working memory capacity or another psychometric measure, we assume that the task employed in order to measure (verbal) working memory capacity pertains to (basic or 'atomic') procedures that also partake in language processing. Using different measures for cognitive 'capacity', or likewise employing different secondary task loads then provides us with a valuable tool to more closely characterise the mechanics of language processing.

\section{Speaking in noise}

For quite some time there have been studies about the effects different acoustic settings might have on human cognition, including our abilities to use language.

Audiological and acoustic research on the so-called cocktail party phenomenon has emphasised the effect on comprehension of the acoustic characteristics of situations with background noise created by multiple speakers talking (see for instance Bronkhorst, 2000). The 'buzz' or 'babble' at cocktail parties possesses particular spectro-temporal acoustic characteristics that are different from 'static' (white or pink) noise. First, the long-term (averaged) frequency spectrum of noise created by multiple talkers has an energy or intensity distribution that has its maximal values in the frequencies contained in speech. Second, the temporal characteristics of such a signal can be described as showing broad-scale fluctuations in amplitude across time, creating an envelope of intensity peaks and troughs, which are partially responsible for creating the 'babble' impression.

In research on language comprehension, noises with different temporal fluctuation parameters have been shown to exert different effects on intelligibility. Temporally fluctuating ('babble') noise has a less detrimental effect on comprehension of language stimuli than constant noise of the same (average) intensity (Wagener, Brand, \& Kollmeier, 2006; Cooke, 2006 and references therein). This difference has been linked to the availability of gaps or "dips" of relative silence in fluctuating noise, which allows for "glimpsing" (Cooke, 2006) at the to-be-comprehended stimulus. The benefit of these glimpses at some (however random) portions of an utterance appears to outweigh, at least on average, the potentially stronger masking of other parts of the 'useful' signal by intensity peaks present in the noise signal.

A different line of research has investigated the effects of cocktail party situations on 
verbally mediated cognitive tasks. After several years, empirical research in attention and memory psychology about the so-called irrelevant speech effect (ISE) has converged upon the finding that concurrent but unattended speech has a detrimental effect on processing for tasks that involve the recalling of (unconnected) verbal material (cf. for instance Banbury, Macken, Sébastien Tremblay, \& Jones, 2001). Somewhat counterintuitively, the effect is independent of intensity or content of concurrent speech (see Klatte, Kilcher, \& Hellbrück, 1995; Ellermeier \& Hellbrück, 1998; Salamé \& Baddeley, 1982). Importantly, the effects of irrelevant auditory stimuli on verbal recall are not limited to irrelevant speech. As Jones and Macken (1993) and Klatte and Hellbrück (1993) have shown, series of intermittent tones or content-free noise lead to performance decreases. What is more, the negative effect on performance is substantially stronger with fluctuating, 'babble-like' noise than with constant noise (Klatte et al., 1995). Hence, these results indicate that simply listening to, or ignoring certain kinds of noise can create a secondary task load on some cognitive tasks.

Since human communication in noisy environments consists of both listening and speaking, and crucially involves the generation of linguistically structured material rather than recalling ordered lists of otherwise unconnected words, an obvious question is whether noise has an impact on the cognitive processes that allow us to produce language.

So far, empirical work that has dealt with the effect of noise on speaking has been for instance concerned with acoustic or prosodic effects, in work on the so-called Lombard reftex or Lombard effect, an increase in perceived articulation effort (Lombard, 1911; see Junqua, Fincke, \& Field, 1999 or Lu \& Cooke, 2008 for more recent work on this effect).

Another line of research investigated the effect of noise on self-monitoring during speaking. Monitoring is a part of the language production process assumed to ensure error-free generation of utterances, by allowing self-interruption and self-repair during speaking (Levelt, 1983, 1989). One mechanism that has been proposed for monitoring of one's own speech is the so-called perceptual loop, which feeds the internal phonological representation, as well as overtly articulated speech back through the comprehension system. The effect of noise on monitoring was investigated by Postma and Noordanus (1996), who tried to block the external loop of speakers producing tongue-twisters by presenting them with white noise at a high intensity through headphones. Apart from a general slowing down of articulation in noise, the authors found a smaller number of self-reported phonological speech errors. This result is taken to mean that monitoring through the external feedback link provides an additional channel to detect errors, which is blocked or impaired in noise. However, it should be noted that the results reported by Postma and Noordanus (1996) pertain to the phonological or lexical level. What is more, the task employed relies on conscious search for errors, which makes it difficult to assess the effect of perceptual monitoring on automatic processing of morphosyntax under a dual-task load.

Finally, language production research from yet another perspective, that of cognitive ageing, provided evidence that there might indeed be an effect of noise on the sentence production process influencing the syntactic level of linguistic structure. A study by Kemper, Herman, and Lian (2003) looked for detrimental effects of secondary tasks on the linguistic complexity of spoken language. One of the secondary tasks was to listen to and ignore cafeteria noise. The authors found an effect of reduced sentence length and grammatical complexity in young, but not in older adults. These results not only again show that ignoring irrelevant noise can generate a secondary task load, but also suggest that this load can impact the generation of linguistic structure during the grammatical encoding stage. 
Still, as Hartsuiker and Barkhuysen (2006) note, the measures employed by Kemper et al. (2003) might be too coarse to precisely pinpoint a potential location of interference. Thus, we investigated this interaction further and looked for more specific effects of irrelevant noise on the formulation process. As a test case we looked at the influence of noise on the generation of agreement between subject and verb in German, and in particular asked whether the amount of agreement errors would be influenced by an external distractor.

\section{Agreement and agreement errors}

Agreement in natural languages marks syntactic relations between elements of a sentence. In the case of agreement between verb and subject, the signalled relation is subjecthood, and since typically the subject bears the external argument role of a verb, the grammatical relation stands for a particular thematic or propositional configuration. This is realised as follows: an agreement target (e. g. the verb) bears identical values for one or more grammatical features as the so-called agreement controller (e. g. the subject of a sentence; Moravcsik, 2006), and this featural identity can then be signalled on a morphological level, for instance by the verb being realised in a particular form that represents a particular setting of feature values.

In German, lexical and auxiliary verbs agree with the subject noun phrase in person and number, to the effect that the verb bears an inflection ending which signals $1^{\text {st }}, 2^{\text {nd }}$ or $3^{\text {rd }}$ person, and singular or plural number respectively.

The generalisation that elements in a sentence signal agreement by sharing features has led to implementations in formal linguistic treatments that require a consistent unification of formal agreement features between for instance a subject noun phrase (NP) and a verb. This is for instance achieved by sharing of indices (cf. e.g. Pollard \& Sag, 1994; Sag, Wasow, \& Bender, 2003; Müller, 2008) or by unifying feature structures (Culicover \& Jackendoff, 2005, cf. also Vigliocco, Butterworth, \& Garrett, 1996; Franck, Vigliocco, \& Nicol, 2002). Mainstream generative accounts in the tradition of the minimalist program (Chomsky, 1995) currently differ slightly in their formal ways to capture agreement. Generally functional heads carrying agreement features are assumed (Agr[eement] or T[ense]; for discussion see Chomsky, 1995), together with a principled requirement for certain positions in a structural configuration to share features (through specifier-head agreement, cf. e.g. Haegeman, 1995; Poole, 2002, or more recently by means of a copying or checking operation under the relation 'Agree', cf. Grewendorf, 2002 and references therein; also compare Radford, 2009). Franck, Lassi, Frauenfelder, and Rizzi (2006) propose a combination of feature checking/copying under 'Agree' and subsequent (re-)checking of features in a specifier-head relation between the subject and the verb.

The production of agreement, especially subject-verb agreement, has proven a highly interesting test case for language production research. Given the abstract nature of the relation it can be seen as a prototypical candidate for a highly automatic grammatical encoding process. In Levelt's psycholinguistic theory of language production (Levelt, 1989; Levelt, Roelofs, \& Meyer, 1999), agreement is computed on the fly during incremental sentence generation. It is generally assumed that the verb is specified for number on the lemma level, either indirectly through spreading of activation from the controller noun's number specification (cf. Bock \& Eberhard, 1993; Eberhard, 1997; Bock, Eberhard, Cutting, Meyer, \& Schriefers, 2001; Eberhard, Cutting, \& Bock, 2005), or in addition to that based 
on conceptual or 'notional' information (cf. Vigliocco et al., 1996). Morphophonological processes retrieve (or assemble) the appropriate verb form based on the specified lemma.

Especially with regard to the question of the origin of the verb's number specification, experimental data about agreement attraction errors has been playing a major role in the development of psycholinguistic models for the computation of agreement for years. Different factors and conditions have been identified that proliferate the occurence of number agreement errors as in example 1 :

(1) "However, it is only the meaning of the words which *have changed, not the grammatical structure of the language."

J. F. Schereschewsky, Hartford Courant, 5 November 1964; quoted after Francis (1986).

In this example the number marking on the verb seems to be 'attracted' by an element other than the actual controller of verb agreement (which is usually the subject in languages like English, French, German or Italian). Quite a number of studies have exploited the attraction effect in order to research the processing of syntactic information in both spoken (Bock \& Miller, 1991; Schriefers \& van Kampen, 1993; Vigliocco \& Nicol, 1998) and written language production (Fayol et al., 1994; Hölscher \& Hemforth, 2000; Hemforth \& Konieczny, 2003), as well as in written language comprehension (Pearlmutter, Garnsey, \& Bock, 1999; Wagers, Lau, \& Phillips, 2009).

Previous studies have tried to assess the role of different (linguistic) factors on the generation of agreement errors. A recurrent, characteristic effect in studies that elicit agreement errors in English is that of plural markedness: Attraction errors are significantly more likely in such cases where the actual agreement controller is marked singular, and a potential attractor with plural marking is present, than in the opposite case (compare examples 2 and 3).

(2) The inscription on the ancient pillars is/*are weathered.

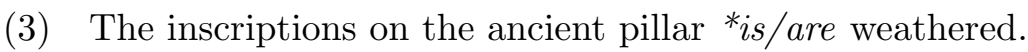

During the production of the verb, the interfering noun's plural marking 'attracts' the agreement control away from the head noun (Bock \& Miller, 1991; Eberhard, 1997).

Already some of the earliest descriptions of attraction errors in the linguistic literature noted an effect of linear distance between agreement controller and an interpolated noun on the likelihood of attraction errors, and consequently dubbed the effect 'proximity concord' (Hale \& Buck, 1903, cited after Francis, 1986; Quirk, Greenbaum, \& Leech, 1989). A study on written production by Fayol et al. (1994) also attributed the occurence of attraction errors to linear order and distance. However, the explanation in terms of a simple function of linear distance was contested by a number of studies that stressed the importance of the structural relation that holds between controller and attractor. Studies comparing different types and depths of embedding of attractors yielded evidence that the strength of the attraction effect also depends on the hierarchical distance between attractor and target (Vigliocco \& Nicol, 1998; Hartsuiker, Antón Méndez, \& van Zee, 2001; Franck et al., 2002), and on the type of interpolated structure, especially in structures with dislocated constituents or when clause boundaries are present. In the formal syntactic model advocated by Franck et al. (2006); Franck, Soare, Frauenfelder, and Rizzi (2010), it is the 'Agree' relation which 
can be difficult to establish in the presence of intervening elements, already in precedence configurations but more so in certain hierarchical configurations (c-command), where even intermediate traces can cause intervention. However, for the structures with a single prepositional phrase modifier used here and in many earlier studies, linear precedence between candidate noun phrases seems to provide the simplest explanation for attraction effects during on-line processing so far (Franck et al., 2010: 169; also see Haskell \& MacDonald, 2005).

Morphophonology appears to play a role in that the informativity or (un- )ambiguity of morphological marking on head and local noun phrase (and their respective determiners) can provide cues that influence the amount of agreement attraction, see for instance Hartsuiker, Schriefers, Bock, and Kikstra (2003); Badecker and Kuminiak (2007), or Franck et al. (2002). We will return to this point in the discussion.

Finally, there is also evidence that conceptual (or 'notional') information can influence the production of agreement as well. Different studies have reported effects of plausibility (Thornton \& MacDonald, 2003), natural gender (Deutsch \& Dank, 2009), and animacy (Bock \& Miller, 1991) on the prevalence of agreement errors. While it emerges quite clearly from these results that some conceptual or notional information can render a non-controller more likely as an attractor, the precise mechanisms underlying these effects on agreement error incidence are still under debate (Eberhard et al., 2005; see discussion).

\section{The current study}

In order to test the influence of situational, external distraction on agreement generation, we conducted a study employing a specially adapted elicitation paradigm in which subjects had to produce sentences under noise, based on sentence preambles they were given as stimuli. In order to avoid noise masking during the perception of the stimuli, we opted for visual presentation of the preambles.

Based on the literature reviewed in the previous sections, we expect that speech-free noise will create a secondary cognitive load that could interfere with language processing. The findings from the ISE literature further predict that temporally structured (fluctuating) noise will lead to stronger disruptions than constant noise. We therefore contrast four different noise conditions: a silent baseline, steady-state noise, and two fluctuating noise signals with a different intensity of the fluctuation.

We are at present unaware of any previous studies that investigated the effects of external noise as a distractor on the production of agreement with the paradigm employed here. Therefore we have no reference point for a quantitative hypothesis about the effect of noise. Still, we expect the additional load generated by the presence of noise to impact the language production process. Given the assumption that secondary task load effects are the result of a competition for processing time on procedures shared between primary and secondary task, we expect a slowing down of language processing. Our hypothesis is that this should lead to an increase in the amount of so-called attraction errors, since the decay of activation should further favour the (erroneous) retrieval of the closer, hence more recently activated attractor noun over the actual controller. 


\section{Sentence elicitation experiment}

\section{Method}

For the experiment we used a sentence elicitation task with rapid serial visual presentation (RSVP) of sentence preambles (Potter, 1984). The (rapid serial, or word-by-word) visual presentation was necessary because part of the presentation would take place under noise, and the noise would partially mask auditorily presented stimuli, introducing an additional, severe source of error to the subject's answers. According to Potter and Lombardi (1998), the serial word-by-word presentation mode is more similar to listening than to conventional reading, given that looking back or ahead is not possible with this way of presentation. Results from their studies indicate that subjects can accurately read and recall sentences shown with RSVP.

\section{Participants}

24 undergraduate and master students, aged between 20 and 28 years $(M=23.6, S D=$ 2.12), participated in the study; half of them were female. Subjects were recruited through an on-line bulletin board announcement, and were paid 7.50 Euro per hour for participation. All participants were naive with regard to the experimental manipulation. Before testing, each subject was screened for hearing acuity with pure-tone audiometry, carried out on an Interacoustics AC40 audiometer. All participants had normal hearing according to WHO standard.

In order to increase statistical power, each participant was tested two times, with at least two weeks in between sessions. Only data from participants that took part in both experimental sessions were used for the analysis.

\section{Material}

20 German test sentences were constructed after the pattern used by Bock and Miller (1991); they consisted of a copula construction with an embedded prepositional phrase (PP) modifying the head of the subject noun phrase (also see Schriefers \& van Kampen, 1993; Hemforth \& Konieczny, 2003; Hartsuiker \& Barkhuysen, 2006). In cases where appropriate, German translations of material from earlier studies were used. The (intended) structure of the sentences was $\left[{ }_{S}\left[N P\right.\right.$ D N[PP $\mathrm{P}\left[{ }_{N P} \mathrm{D}\right.$ ADJ N $\left.\left.]\right]\right] \mathrm{V}_{A U X}$ ADJ], see example 4.

(4) Die Inschrift-en ${ }_{H E A D}$ auf der antik-en Säule $L O C A L$ sind verwitter-t. the inscription-PL on the ancient-SG pillar;SG are weather-PTCP 'The inscriptions on the ancient pillar are weathered.'

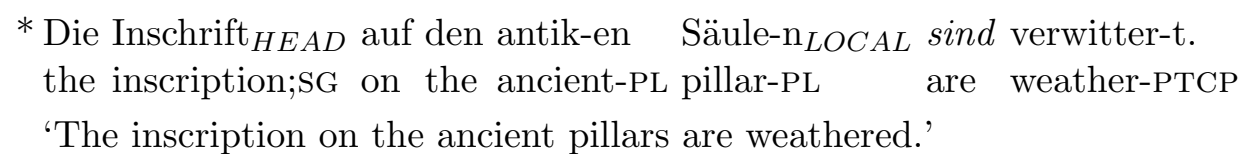

For each of the sentences, two nouns and respective adjectives were combined to form plausible propositions. Nouns and adjectives used in the sentences were controlled for word length in syllables, as well as for frequency class according to the Leipziger Wortschatz database (Biemann, Bordag, Heyer, Quasthoff, \& Wolff, 2004), so that lexical elements 
within an individual sentences would not stand out on either of the two measures. An adjective was added to the interpolated prepositional phrase, in order to increase the distance between subject head noun and verb.

Number marking on head and local NPs was manipulated to yield four different versions per sentence. For that, we combined the two factors match (head and local noun match/mismatch in number) and head noun number (singular/plural).

To pretest the items, we carried out an online questionnaire study with 90 participants (all native speakers of German, 23 male, 67 female; aged between 19 and 59, $M=24.6$, $S D=5.21$ ). The questionnaire asked for a plausibility rating about each sentence, given a scale ranging from 1 to 4 . Based on the rating results, we removed items where the difference in plausibility between the four different head/local NP number combinations reached significance, and items where the overal standard deviation was above 0.9. This left us with 20 experimental items, with four sentence versions per item (see appendix A for a list of items).

For the experiment, the four number marking conditions (singular match [sg-sg], plural match [pl-pl], singular mismatch [sg-pl], plural mismatch [pl-sg]) were counterbalanced across four noise condition blocks, so that one combination of nouns never appeared more than once within one block. Four experimental lists were created with different counterbalancings of material across blocks.

The experimental lists were pseudorandomly interspersed with filler items taken from the OLACS corpus of stimulus sentences (Uslar et al., 2010). Care was taken to limit the number of succeeding experimental items to three in all cases. The filler material consisted of 160 sentences, 80 relative clauses and 80 simple transitive clauses (see examples 6 and 7).

(6) Der freche Kasper tadelt den stolzen Clown. the; NOM cheeky buffoon reprimands the;ACC proud clown.

'The cheeky buffoon is reprimanding the proud clown.'

(7) Der Soldat, der die Köchinnen tadelt, schwitzt. the;NOM soldier, who the;ACC chefs; F reprimands, sweats.

'The soldier, who is reprimanding the female chefs, is sweating.'

Four different sentence types per filler structure were used: both SVO and OVS sentences with and without plural subject, as well as subject and object relative clauses with and without plural RC subject. Overall, if a subject noticed the number manipulation in the material, what he or she experienced was variation of the number of different NPs across three different structures. ${ }^{3}$

Each sentence in the experiment was 8 words long, and always the second to last word was replaced by an underscore that indicated the gap participants had to fill. Across critical and filler sentences, subjects were required to complete gaps with either an adjective or a full verb in the filler items, or an copula (auxiliary) verb for the critical items.

\section{Procedure}

After briefing and screening, subjects were seated in front of a 19-inch LCD screen in a dimly lit sound attenuated booth. They were instructed to attend to a fixation cross on

\footnotetext{
${ }^{3}$ Upon debriefing, all subjects reported that they had not been aware of the experiment's goal to elicit attraction errors, even if they had noticed the different number markings.
} 
the screen and to a sentence containing a gap, which would be presented in a word-by-word fashion. Subjects were asked to read the sentence, wait for an answer prompt after the complete presentation and then speak aloud the sentence they had read, including their completion of the missing word.

The exact timing of an individual trial is shown in figure 1 on page 28 .

(FIGURE 1 ABOUT HERE)

After a 1000 msec fixation cross the sentence appeared in a word-by-word fashion, containing a slide with underscores marking the gap. The end of the sentence was indicated by a period after the last word. Following the final word a visual mask appeared for 500 msec, consisting of a row of hash signs (\#). The mask was followed by the production prompt, a single question mark at the center of the screen. The prompt lasted for 4500 msec, during which subjects had been instructed to respond. After an ITI of $1500 \mathrm{msec}$ the next trial started. In the noise conditions a pre-recorded distractor noise sound was presented, starting after the fourth word of a sentence, and lasting until the end of the trial.

Audiovisual stimulus presentation and sound recording was carried out with E-Prime Pro 2 software (Psychology Software Tools, Inc.). Recordings were made with a low-latency sound adaptor (ECHO Audio Gina 3G) and a microphone with cardioid recording characteristics (AKG C 1000-S), attached to the presentation PC. For sound presentation, we used two Genelec 8030A active near-field speakers. Before the study, the computer setup was calibrated with a Brüel \& Kjær sound pressure level (SPL) meter, so that with fixed hard- and software settings we would reach a root mean square (RMS) SPL of noise of 68 $\mathrm{dB}$ at the approximate position of the participant's heads. The sound files used to present distractor noise were adjusted to identical RMS intensity levels.

Apart from silence which served as baseline condition, we used three different noise signals as distractor stimuli. The signals are part of the International Collegium of Rehabilitative Audiology (ICRA) set of standardised noises for audiological research, simulating spectral and or temporal characteristics of human speech (Dreschler, Verschuure, Ludvigsen, \& Westermann, 2001). We chose one unmodulated signal (ICRA 1), with long-term spectrum characteristics of speech ('pink' noise), a modulated signal simulating the prosodic contour of one speaker at small distance (ICRA 4), and a signal simulating six talkers speaking at the same time (ICRA 7). The ICRA 4 signal was used because experiments on language perception have found large detriments on intelligibilty with speech masked by this type of fluctuating sound (Wagener et al., 2006). We included the ICRA 7 'babble' sound as well, because is conceptually closest to a "cocktail party" setting (Bronkhorst, 2000). The noise conditions were blocked, in order to reduce surprisal effects. Block order was counterbalanced across participants and each participant received a different block order on each of the two experimental sessions.

\section{Scoring}

Only answers that conformed to the intended structure (see example 4 on page 10) were analysed. The subjects' answers were scored manually, recording the produced number of both head and local noun as well as the number marked on the verb. An answer was scored as containing an agreement error if the respective number markings on subject head noun and verb did not match. Ungrammatical structures, sentences that did not conform to the intended structure, or unintelligible answers were scored as 'other'. Table 1 on page 30 
provides an overview over the relevant sentences structures produced by participants.

(TABLE 1 ABOUT HERE)

\section{Design and Analysis}

Data from the two sessions per participant were pooled. Since we could not exclude the possibility that participants had misread one of the visually presented sentences, we disregarded the head/local noun number configuration that was presented, and analysed only the sentence form that subjects actually produced. This introduced some variation across conditions, in effect subjects did not produce exactly equal amounts of each configuration (see table 1). A $\chi^{2}$ test did not reach significance, however, indicating that subjects still produced approximately equal amounts of sentences in the four number marking $\times$ match conditions $\left(\chi^{2}(1, N=3703)=2.7628, p=.0965\right)$.

The data were analysed using a generalised logistic mixed modeling (GLMM) approach (Baayen, Davidson, \& Bates, 2008; Baayen, 2008; Jaeger, 2008) with error as outcome variable, and noise, match and head noun phrase number (as produced) as predictors. Subjects and items (here: noun-pairs, disregarding the different number cofigurations) were treated as random effects. First, a simple model was specified based on previous results in the literature, to test the results from the baseline silence condition for a mismatch effect. The same model was also fitted to the entire data set from the experiment, initially marginalising over noise conditions. Using the anova() procedure of the $\mathrm{R}$ software ( $\mathrm{R}$ Development Core Team, 2010; cf. also Baayen et al., 2008), an implementation of a loglikelihood ratio test comparing (Laplace) quasi log-likelihoods, we added noise as a factor and tested for possible interactions with noise by comparing it to the simpler model, as an omnibus test for the factor noise.

\section{Results}

Figure 2 on page 29 summarises the amount of errors as a function of the match and head NP number conditions in the four different noise conditions.

(FIGURE 2 ABOUT HERE)

When looking at the data from our silent condition only, we find that the amount of errors is significantly higher in the singular mismatch than in the singular match condition (see model summary in table 2 on page 31 ). The interaction between head noun number and match condition barely missed significance, indicating an agreement attraction effect in the mismatch singular ( $\mathrm{sg}-\mathrm{pl})$ condition.

(TABLE 2 ABOUT HERE)

As described in the previous section, we fitted several models with and without noise condition as a predictor, in order to assess the influence of noise on agreement error incidence. As a result of the model comparison, we see that noise proved to have a significant effect on error incidence $\left(\chi^{2}(9)=20.066, p<.05\right)$.

Crucially, three interactions of error likelihood with noise reached significance: When either of the two fluctuating noises was present, the amount of errors increased in sentences with either of the two nouns marked for plural. What is more, under the single-talker babble (ICRA4), the amount of errors in the mismatch condition is reduced compared to silence. Constant noise (ICRA 1) did not affect the error distribution. 
3-way interactions between noise, match and subject noun number did not improve model fit and were removed from the specification. Table 3 on page 32 summarises the final model including noise as a factor.

(TABLE 3 ABOUT HERE)

\section{Discussion}

The results from our baseline (silence) condition indicate an agreement attraction effect, including the characteristic asymmetry of errors ocurring more frequently after a plural attractor noun. These results replicate the plural markedness effect in attraction (Bock \& Miller, 1991; Eberhard, 1997; Hartsuiker et al., 2003): a local attractor noun with plural number marking leads to a higher amount of agreement errors. This asymmetry is in line with a number of reports about experiments in English (Bock \& Miller, 1991), Dutch, German (Hartsuiker et al., 2003), Italian, Spanish (Vigliocco et al., 1996), and French (Fayol et al., 1994).

Crucially, the omnibus test for an effect of noise on the pattern of agreement errors shows that subjects were influenced by the noise manipulation. This confirms our first hypothesis and we take this as evidence that indeed external noise can influence the sentence production process by creating a secondary task load.

What is more, a highly interesting outcome is the fact that only fluctuating noise conditions entered significant interactions with other factors. Constant noise had no measurable effect on the distribution of errors. This finding also confirms our expectations, which were based on results from the literature on the irrelevant sound effect (e. g. Klatte et al., 1995), where it has been suggested that detrimental effects on performance result from interference by changing-state noise, but not from interferences by constant noise.

As the coefficients from the final model with noise as a factor indicate, the distribution of errors across the MATCH by NUMBER conditions changes. Error rates increased significantly under fluctuating noise, whenever the head noun was plural. In addition to that, we found a slight decrease of errors in the singular mismatch condition under the strongly fluctuating, 'single talker babble' noise condition (ICRA 4). This pattern is different from the increase in attraction errors in the singular mismatch condition ( $\mathrm{sg}-\mathrm{pl}$ ) we had expected. Rather, the plural effect we observe means that under fluctuating noise subjects actually produced more verbs wrongly marked for singular after a plural head. This is surprising especially for the plural match (pl-pl) condition, where the plural markings on both the head noun and the attractor do not provide conflicting cues for word form retrieval. If a plural local noun is assumed to exert an attraction effect, in the plural match condition a spurious number assignment based on the local noun's number marking should result in (coincidentally) correct number marking.

The plural effect we observe might be the result of an increase in 'default' singular number markings. This would also explain the decrease in attraction errors under the ICRA 4 fluctuating noise, as a tendency to produce singular marked verb forms would counteract the attraction effect and lead to accidentally correct answers. A 'default' marking or singular bias has been suggested earlier by Hemforth and Konieczny (2003) as an explanation of their results from a written sentence completion study; also see Franck et al. (2004) for a similar argument based on acquisition data. 
A default status for singular number is a central part of the explanation of the plural markedness effect by Eberhard (1997), who assumes number marking to be 'privative' or unary. The featureless, or 'unmarked' case is assumed to be singular, and Eberhard (1997) presents evidence for the psychological reality of the unary specification of number by a grammatical feature. In linguistic descriptions, a number of authors have attributed plural number a 'marked' status over singular on phonetic, morphological and conceptual or semantic grounds, see for instance Greenberg (1966), Givón (1991), or Wurzel (1998). However, in a critical evaluation of the usage of the term 'markedness', Haspelmath (2006) suggests to dispense with it and replace it by theoretically more substantive concepts, such as phonetic lenght or (lexical) frequency. And in fact, there is ample evidence that for instance frequency plays a major role in word form access for both perception and production, as word forms with a higher token frequency can be more easily or rapidly accessed (Oldfield \& Wingfield, 1965; Stemberger, 1984, 1985; Jescheniak \& Levelt, 1994). But the story is not quite that simple, since studies on morphological processing have shown that word form or token frequency alone seems to be an insufficient predictor of processing speed. The work by Kostić and Katz (1987); Kostić (1991) on Serbo-Croatian and related work has shown that while frequency affects lexical access in both comprehension and production, the paradigmatic ordering of inflected word forms and syncretism within the paradigm plays an important role as well. This notion can be numerically captured as the entropy, or informational content of a particular form as a result of the functional transparency of a form and/or paradigm (Kostić, 1991, also see Milin, Filipović Djurdjević, \& Moscoso Del Prado Martín, 2009; Van Ewijk \& Avrutin, 2010; Baayen, Levelt, Schreuder, \& Ernestus, 2007). ${ }^{4}$

Both frequency as well as information content influence processing latency, for instance in lexical decision experiments. While frequency is positively correlated with latency, the amount of syncretism within a paradigm appears to increase its complexity and hence decision RT (Milin et al., 2009; Van Ewijk \& Avrutin, 2010)-leading to an interaction between frequency and distributional properties within a paradigm. Kostić (1991) captures this insight in his calculation of entropy as the average relative frequency per function of a particular word form.

In the context of our present study, a superficial check of lexical frequencies of the verb forms of the German verb 'sein' (to be) with the Leipziger Wortschatz database reveals that the $3^{\text {rd }}$ person singular form 'ist' is at least one order of magnitude more frequent than the respective plural form 'sind'. This is also confirmed by frequency counts from the CELEX database (Max Planck Institute for Psycholinguistics, 2001; Baayen, Piepenbrock, $\&$ Gulikers, 1995). Based on frequency data from the CELEX corpus, we used the formula suggested by Kostić (1991) to calculate a rough entropy estimate for the different word forms of the auxiliary verb 'sein' (to be), which was used by almost all of our experimental subjects for the completion of the test sentences. Our rough estimate for information content provides further evidence for a default status of the $3^{\text {rd }}$ person singular form of the verb 'sein' over the respective plural form. Hence, the higher number of singular forms produced under noise can be related to the default status of singular, be it in terms of the word form frequency or in terms of informational content or complexity of the singular form.

\footnotetext{
${ }^{4}$ The operationalisation of entropy differs slightly between authors, as the studies cited ask different questions and apply different frames of reference for the calculation of relative frequencies.
} 
How could fluctuating noise lead to a stronger reliance of subjects on the default or unmarked form? In order to explain this effect, we have to consider how the influence of noise could be captured by existing accounts of the mechanism for agreement marking and the generation of attraction errors.

First, a crucial explanatory step involves the question how noise can influence cognition at all. Research on the irrelevant sound effect (ISE) has produced a number of different theoretical accounts over the years. The models differ in terms of the conception of working memory they imply, and consequently with respect to the mechanism for the interference effect on the serial recall task induced by irrelevant sound. Models based on the Phonological Loop (Salamé \& Baddeley, 1982; Baddeley, 1986), and the Object-Oriented Episodic Record model (O-OER; Jones, 1993; Jones, Madden, \& Miles, 1992; Macken, Tremblay, Alford, \& Jones, 1999) share the assumption that irrelevant sound is automatically and obligatorily processed in memory, and the concurrent processing draws on resources shared with the task of retaining an ordered list. Of these two kinds of model, only the O-OER suggests a precise mechanistic explanation for the interference of non-speech sounds. With their changing state hypothesis, Jones and Macken (1993) and Macken et al. (1999) emphasise the role of the structured nature of both speech as well as fluctuating, non-speech distractor sounds. The authors suggest that any structured sound signal is automatically subjected to auditory scene analysis, which tries to extract an ordered sequence of auditory objects from the signal. The hypothesis predicts that processing for the primary task of maintaining an ordered list of words in working memory will compete for processing resources on a seriation process, that would be engaged concurrently by automatic auditory scene analysis.

As we noted in the introduction, the task of producing sentences with correct agreement cannot be straightforwardly compared to the serial verbal recall tasks usually employed to investigate irrelevant sound effects. However, maintenance of the order of elements might be a basic function that subserves sentence generation and the computation of agreement at some point during on-line processing. Competition for processing time on a seriation mechanism should lead to a slowing down of concurrent language processing. Our present data does not allow for a straightforward decision between different processing models for agreement production, but we will discuss three accounts and try to evaluate how they allow for an explanation of the effects we observe, and whether they can be integrated with the proposal of competition for processing time on a seriation mechanism in a non-trivial fashion.

First, however, we turn to an explanation based on monitoring through the perceptual loop (Levelt, 1983, 1989). A study by Hartsuiker et al. (2003) evaluated the effects of morphophonology on the production of agreement errors and discussed several mechanisms for feed-back of auditory information during speaking. They propose a filtering account that is based on phonological form information accessible through an internal monitoring loop (see also Fayol et al., 1994; Hartsuiker \& Barkhuysen, 2006). The filtering process is conceived of as requiring attentional resources. The authors argue that errors can be more easily intercepted if the fed-back form contains unambiguous number marking cues. Since in our study the distractor noise affects the overt, acoustic form of the subject's own speech, we would have to adapt the filtering account in order to explain an effect of noise on agreement error production through monitoring via the external loop. A possible mechanism could rely on the phonological representation of the two nouns in working memory to check the result of the verb's number specification. Under noise, the phonological representation of 
the nouns is impoverished or subject to faster decay, and the checking process will fail. ${ }^{5}$ There is a significant drawback to this account, however: If our observations are the result of external noise masking the phonological representation of one's own speech, we would expect a similar effect under constant noise as well. Our results indicate that this is not the case, however, which speaks against an explanation based on monitoring through the external perceptual loop.

Other psycholinguistic models for the agreement marking process have been proposed which strive to account for the mechanisms of making agreement errors at the level of grammatical encoding. The models differ with respect to the precise locus of erroneous processing. The 'attraction' effect proper involves the incorrect (that is, ungrammatical; cf. Wagers et al., 2009: 209) specification of a subject NP with the number marking of a constituent which does not form its head (Vigliocco et al., 1996; Vigliocco \& Nicol, 1998; Bock et al., 2001; Eberhard et al., 2005). This effect has been modelled with spreading activation networks, for instance by Eberhard (1997) and Eberhard et al. (2005).

In the computational implementation of the model by Eberhard et al. (2005), activation representing grammatical number information spreads through the network and influences the probabilities of the respective verb forms to be retrieved, depending on the activation level of the number information. Both the subject head noun phrase (NP) as well as the local attractor serve as sources for activation; the attraction effect follows from the architecture of the model, especially from the source activation values and the representation of structure as nodes altering the activation level. We might speculate that a slowing down of processing as a result of noise could lead to decay of feature activation for both the agreement controller as well as the attractor NP, resulting in a higher number of unmarked verb forms being produced. However, other than the earlier conception in Eberhard (1997), the newer model does not explicate a time-based decay mechanism for features. Thus, with regard to its architecture, the conception is presently difficult to reconcile with the assumption of a seriation mechanism as proposed by Jones, Macken and colleagues.

The working memory retrieval model (Lewis \& Vasishth, 2005, also see Badecker \& Kuminiak, 2007; Wagers et al., 2009) is based on a conception of sentence processing as a series of cue-based working memory retrieval processes. Lewis and Vasishth (2005) recently formalised and implemented such an approach in the ACT-R cognitive architecture (Adaptive Control of Thought-Rational; see for instance Anderson et al., 2004; Anderson, 2007), as a model for real-time sentence comprehension. They model syntactic structure in the form of feature bundles or 'chunks' in memory for each maximal projection, with hierarchical relations between these objects encoded as feature-value pairs. A set of production rules implements procedural knowledge, including grammatical constraints. Syntactic structure is computed 'on-the-fly', incrementally by procedures that dynamically retrieve chunks in memory and set the relevant retrieval cues for further, super- or subordinate structural elements. Retrieval cues are (sub-)sets of formal features that allow to identify other constituents, including previously activated ones. For some operations, the re-retrieval of previously activated elements is required, and this reactivation of chunks is based on an associative, cue-based memory search mechanism, which is hypothesised to be subject to similarity-based interference (e. g. Lewis \& Vasishth, 2005; Lewis, Vasishth, \& Van Dyke,

\footnotetext{
${ }^{5}$ This explanation is in fact very similar to accounts for the ISE based on interference between items stored in the phonological loop of Baddeley's working memory model.
} 
2006; McElree, Foraker, \& Dyer, 2003; also see Gordon, Hendrick, \& Johnson, 2001; Gordon, Hendrick, \& Levine, 2002). Another crucial characteristic of the memory system as specified by Lewis and Vasishth (2005) is the decay of an item or chunk's activation as a (non-linear) function of time.

Badecker and Kuminiak (2007) employ the notion proposed by Lewis \& Vasishth's model about the necessary reactivation of chunks in working memory based on retrieval cues for a model of agreement error production. Since sentence generation proceeds in an incremental fashion, the authors argue, earlier parts of the structure have to be re-retrieved and brought back into the working memory 'focus' for further processing (McElree, 2001; see also Cowan, 2001; Berti, 2010). In processing for production of agreement, the subject noun phrase as the correct agreement controller has to be reactivated at the verb site, in order for the noun phrase's number specification to be accessed, so that a correctly inflected verb form can be retrieved. Possible retrieval cues include structural features like syntactic category, (nominative) case, features representing structural positions or grammatical functions (Lewis \& Vasishth, 2005; Badecker \& Kuminiak, 2007; Wagers et al., 2009). According to this account, agreement errors occur when there is interference from another, likely candidate that is sufficiently similar to the actual agreement controller and a wrong cue is set for retrieval of an inflected verb form.

The working memory retrieval account seems to be more readily compatible with an explanation of fluctuating noise effects in terms of competition for a seriation process and a subsequent slowing down of processing. ${ }^{6}$ Under the retrieval account, the verb's number feature is specified based on the features of a candidate noun phrase, which has to be reactivated from immediate memory. A set of grammatical features is used as search cues to identify possible candidates. If the search makes use of serial order cues to identify the absolute or relative position of earlier elements, a competition for processes establishing or maintaining this serial order might lead to a slowing down of processing and retrieval of an incorrect agreement controller candidate (cf. Badecker \& Kuminiak, 2007: 82). During normal processing, the plural number marking on the reactivated subject head NP (or the marking of the spuriously retrieved non-head NP respectively) yields a strong cue for the activation of a plural verb form. If under fluctuating noise processing is slowed down, retrieval of the agreement controller noun phrase can in some cases take too long, and an empty (or 'default') number specification is used as a cue for the retrieval of the verb form. Alternatively, the plural cue might be set too late during verb form retrieval, so that the default verb form will win by means of a head start in activation because of its higher frequency. Under both construals the effect of fluctuating noise we observe is not an effect of attraction as such, but rather follows from the defaulting to singular verb forms, which are inappropriate after a plural head noun.

To sum up, the explanation in terms of working memory retrieval allows us to capture both the agreement attraction effect in silence, as well as the subjects' resorting to default or unmarked singular verb forms under fluctuating noise, resulting in an increase in agreement errors after a preamble with a plural head NP and a plural attractor NP. Such a mechanistic hypothesis has the advantage of being highly explicit in terms of the pro-

\footnotetext{
${ }^{6}$ Note however that for the specification of their ACT-R model for sentence comprehension, Lewis and Vasishth (2005) explicitly dispense with serial order information, based on considerations about processing speed (Lewis \& Vasishth, 2005: 404; McElree, 2001). Still, they maintain that making use of order cues remains a tenable function during processing.
} 
cessing steps involved, at the same time dispensing with problematic energetic notions of 'capacity' or 'resources', by relying solely on a competition for processing time on a basic cognitive function (Rummer et al., 1998; Lewis \& Vasishth, 2005). Importantly, our finding that something as common or unspecific as background noise can influence grammatical encoding speaks against the assumption that the formulation stage operates in a highly automatic fashion with dedicated, or 'exclusive' processing resources at its disposal (Ferreira \& Pashler, 2002; Hartsuiker \& Barkhuysen, 2006). The view that processing under dualtask conditions leads to interference between basic processing steps or 'functions' that are shared between cognitive tasks presents exciting opportunities to further investigate the complex processing mechanisms involved in production (and comprehension), in order to dissociate domain-general and domain-specific processing functions (cf. for instance Barrett \& Kurzban, 2006).

Moreover, it has been claimed that the type of sentences we used, with a prepositional phrase subject modifier, elicit weaker attraction effects than other structures with hierarchical intervention (Franck et al., 2010). This means that even small effects found in the NP-PP structures when listening to noise provide a strong argument for the influence of noise on production. Further research should tackle the influence of noise on agreement attraction under different intervention conditions (hierarchical interveners, intervention of intermediate traces).

\section{Conclusion}

For the current study we successfully influenced the grammatical encoding stage during language production with non-speech noise. According to our current knowledge, this is the first time that the effect of an external, situational non-speech distractor on the production of agreement was established. As predicted by a hypothesis from research on the irrelevant sound effect, it is particularly noise with broad-scale intensity fluctuations that exerted a detrimental effect on the production of agreement and we claim that the acoustic properties of the noise we used have an influence on the representation of linguistic structure in memory by means of competition for processing time on a basic cognitive functions that is shared between different processing 'domains'.

Our current findings do not allow us to conclusively distinguish between different proposals for a mechanism for the influence of noise on speaking. However, we believe that the changing-state hypothesis we adopted makes clear theoretical commitments with respect to the effect of a particular characteristic of noise on cognition and thus provides us with a new hypothesis about the role of serial order cues on language processing. Going from here, more candidates for perceptual or general cognitive processes that subserve language processing should be identified and tested.

\section{A. Stimuli}

1. Die Beschwerde/n von der/den engagierten Schülerin/nen ist/sind begründet. "The complaint/s by the dedicated student/s is/are justified."

2. Die Grafik/en in der/den farbigen Broschüre/n ist/sind deutlich. 
"The figure/s in the colorful brochure/s is/are clear."

3. Die Inschrift/en auf der/den antiken Säule/n ist/sind verwittert.

"The inscription/s on the ancient pillar/s is/are weathered."

4. Die Visite/n auf der/den chirurgischen Station/en ist/sind beendet.

"The round/s of the surgical ward/s is/are finished."

5. Die Affäre/n um den/die berühmten Spion/e ist/sind übertrieben.

"The scandal/s about the famous spy/spies is/are exaggerated."

6. Die Abbildung/en auf der/den begehrten Tasse/n ist/sind hübsch.

"The picture/s on the sought-after cup/s is/are pretty."

7. Die Zeitschrift/en mit dem/den peinlichen Fehler/n ist/sind unauffindbar.

"The newspaper/s with the embarrassing mistake/s is/are untraceable."

8. Die Lücke/n in der/den merkwürdigen Theorie/n ist/sind unübersehbar.

"The gap/s in the awkward theory/theories is/are highly visible."

9. Die Kooperation/en mit dem/den gewerblichen Händler/n ist/sind fruchtbar. "The cooperation/s with the commercial dealer/s is/are fruitful."

10. Die Tracht/en mit dem/den typischen Muster/n ist/sind begehrt.

"The traditional costume/s with the typical pattern/s is/are sought-after."

11. Die Beschreibung/en in dem/den aktuellen Reiseführer/n ist/sind undeutlich. "The description/s in the up-to-date travel guide/s is/are unclear."

12. Die Anweisung/en auf dem/den internen Rundschreiben/n ist/sind fehlerhaft. "The direction/s in the internal newsletter/s is/are inaccurate."

13. Die Manipulation/en an der/den komplizierten Maschine/n ist/sind gefährlich. "The manipulation/s of the complex machine/s is/are dangerous."

14. Die Anzeige/n in der/den erneuerten Bahn/en ist/sind beleuchtet. "The display/s in the renovated train/s is/are lit."

15. Die Versammlung/en vor der/den geschlossenen Filiale/n ist/sind unerwartet. "The gathering/s in front of the closed store/s is/are unexpected."

16. Die Unterschrift/en auf der/den verbindlichen Erklärung/en ist/sind gefälscht. "The signature/s on the binding declaration/s is/are forged."

17. Die Behandlung/en mit dem/den neuartigen Medikament/en ist/sind wirksam. "The treatment/s with the novel drug/s is/are effective."

18. Die Panne/n in der/den verarbeitenden Fabrik/en ist/sind katastrophal. "The accident/s in the processing factory/factories is/are catastrophic."

19. Die Veränderung/en an der/den gültigen Richtlinie/n ist/sind minimal. "The change/s to the effective regulation/s is/are minimal." 
20. Die Forderung/en nach der/den umfangreichen Reform/en ist/sind unseriös.

"The demand/s for the substantial reform/s is/are unsound." 


\section{References}

Anderson, J. R. (2007). How Can the Human Mind Occur in the Physical Universe? New York: Oxford University Press.

Anderson, J. R., Bothell, D., Byrne, M. D., Douglass, S., Lebiere, C., \& Qin, Y. (2004). An Integrated Theory of the Mind. Psychological Review, 111(4), 1036-1060.

Baayen, R. H. (2008). Analyzing Linguistic Data: A Practical Introduction to Statistics using R. Cambridge: Cambridge University Press.

Baayen, R. H., Davidson, D. J., \& Bates, D. M. (2008). Mixed-effects modeling with crossed random effects for subjects and items. Journal of Memory and Language, 59, 390-412.

Baayen, R. H., Levelt, W. J. M., Schreuder, R., \& Ernestus, M. (2007). Paradigmatic structure in speech production. Proceedings from the Annual Meeting of the Chicago Linguistic Society, 43(1), 1-29.

Baayen, R. H., Piepenbrock, R., \& Gulikers, L. (1995). The CELEX Lexical Database (CDROM). Philadelphia, PA: Linguistic Data Consortium, University of Pennsylvania.

Baddeley, A. (1986). Working memory. Oxford: Clarendon.

Baddeley, A. (2003). Working Memory: Looking back and looking forward. Nature Reviews Neuroscience, 4, 829-839.

Badecker, W., \& Kuminiak, F. (2007). Morphology, agreement and working memory retrieval in sentence production: Evidence from gender and case in Slovak. Journal of Memory and Language, 56, 65-85.

Banbury, S. P., Macken, W. J., Sébastien Tremblay, \& Jones, D. M. (2001). Auditory Distraction and Short-Term Memory: Phenomena and Practical Implications. Human Factors, 43(1), 12-29.

Barrett, H. C., \& Kurzban, R. (2006). Modularity in cognition: Framing the debate. Psychological Review, 113(3), 628-647.

Berti, S. (2010). Arbeitsgedächtnis: Vergangenheit, Gegenwart und Zukunft eines theoretischen Konstruktes [Working memory: the past, the present, and the future of a theoretical construct]. Psychologische Rundschau, 61(1), 3-9.

Biemann, C., Bordag, S., Heyer, G., Quasthoff, U., \& Wolff, C. (2004). LanguageIndependent Methods for Compiling Monolingual Lexical Data. Lecture Notes in Computer Science, 2945, 217-228. doi: 10.1007/978-3-540-24630- 527

Bock, K., Dell, G. S., Garnsey, S. M., Kramer, A. F., \& Kubose, T. T. (2007). Car talk, car listen. In A. S. Meyer, L. R. Wheeldon, \& A. Krott (Eds.), Automaticity and control in language processing (pp. 21-42). Hove: Psychology Press.

Bock, K., \& Eberhard, K. M. (1993). Meaning, Sound and Syntax in English Number Agreement. Language and Cognitive Processes, 8(1), 57-99.

Bock, K., Eberhard, K. M., Cutting, J. C., Meyer, A. S., \& Schriefers, H. (2001). Some Attractions of Verb Agreement. Cognitive Psychology, 43, 83-128.

Bock, K., \& Levelt, W. J. M. (1994). Language Production: Grammatical Encoding. In Morton Ann Gernsbacher (Ed.), Handbook of Psycholinguistics (pp. 945-984). San Diego, CA: Academic Press.

Bock, K., \& Miller, C. A. (1991). Broken Agreement. Cognitive Psychology, 23(1), 45-93.

Bronkhorst, A. W. (2000). The cocktail party phenomenon: A review of research on speech intelligibility in multiple-talker conditions. Acustica, 86(1), 117-128. 
Caplan, D., \& Waters, G. S. (1999). Verbal working memory and sentence comprehension. Behavioral and Brain Sciences, 22(1), 77-126.

Chomsky, N. (1995). The minimalist program. Cambridge, MA: MIT Press.

Conway, A. R. A., Kane, M. J., Bunting, M. F., Hambrick, D. Z., Wilhelm, O., \& Engle, R. W. (2005). Working memory span tasks: A methodological review and user's guide. Psychonomic Bulletin \& Review, 12(5), 769-786.

Cooke, M. (2006). A glimpsing model of speech perception in noise. Journal of the Acoustical Society of America, 119(3), 1562-1573. doi: 10.1121/1.2166600

Cowan, N. (2001). The magical number 4 in short-term memory: A reconsideration of mental storage capacity. Behavioral and Brain Sciences, 24, 87-114.

Culicover, P. W., \& Jackendoff, R. (2005). Simpler Syntax. Oxford: Oxford University Press.

Daneman, M., \& Carpenter, P. A. (1980). Individual Differences in Working Memory and Reading. Journal of Verbal Learning and Verbal Behavior, 19(4), 450-466.

Deutsch, A., \& Dank, M. (2009). Conflicting cues and competition between notional and grammatical factors in producing number and gender agreement: Evidence from Hebrew. Journal of Memory and Language, 60(1), 112-143.

Dreschler, W. A., Verschuure, H., Ludvigsen, C., \& Westermann, S. (2001). ICRA noises: Artificial noise signals with speech-like spectral and temporal properties for hearing instrument assessment. Audiology, 40(3), 148-157.

Eberhard, K. M. (1997). The Marked Effect of Number on Subject-Verb Agreement. Journal of Memory and Language, 36, 147-164.

Eberhard, K. M., Cutting, J. C., \& Bock, K. (2005). Making Syntax of Sense: Number Agreement in Sentence Production. Psychological Review, 112(3), 531-559.

Ellermeier, W., \& Hellbrück, J. (1998). Is Level Irrelevant in "Irrelevant Speech"? Effects of Loudness, Signal-to-Noise Ratio, and Binaural Unmasking. Journal of Experimental Psychology: Human Perception and Performance, 24(5), 1406-1414.

Fayol, M., Largy, P., \& Lemaire, P. (1994). Cognitive Overload and Orthographic Errors: When Cognitive Overload Enhances Subject-Verb Agreement Errors. A Study in French Written Language. The Quarterly Journal of Experimental Psychology, 47A(2), 437-464.

Ferreira, V. S., \& Pashler, H. (2002). Central bottleneck influences on the processing stages of word production. Journal of Experimental Psychology: Learning, Memory, and Cognition, 28(6), 1187-1199.

Fodor, J. A. (1983). The modularity of mind. Cambridge, MA: MIT Press.

Francis, W. N. (1986). Proximity Concord in English. Journal of English Linguistics, 19, 309-317.

Franck, J., Cronel Ohayon, S., Chillier, L., Frauenfelder, U. H., Hamann, C., Rizzi, L., \& Zesiger, P. (2004). Normal and pathological development of subject-verb agreement in speech production: a study on French children. Journal of Neurolinguistics, 17, $147-180$.

Franck, J., Lassi, G., Frauenfelder, U. H., \& Rizzi, L. (2006). Agreement and movement: A syntactic analysis of attraction. Cognition, 101(1), 173-216.

Franck, J., Soare, G., Frauenfelder, U. H., \& Rizzi, L. (2010). Object interference in subject-verb agreement: The role of intermediate traces of movement. Journal of Memory and Language, 62, 166-182. 
Franck, J., Vigliocco, G., \& Nicol, J. (2002). Subject-verb agreement errors in French and English: The role of syntactic hierarchy. Language and Cognitive Processes, 17(4), 371-404.

Garrod, S., \& Pickering, M. J. (2007). Automaticity of language production in monologue and dialogue. In Antje S. Meyer, Linda R. Wheeldon, \& Andrea Krott (Eds.), Automaticity and control in language processing (pp. 1-20). Hove: Psychology Press.

Givón, T. (1991). Markedness in grammar: distributional, communicative and cognitive correlates of syntactic structure. Studies in Language, 15(2), 335-370.

Gordon, P. C., Hendrick, R., \& Johnson, M. (2001). Memory interference during language processing. Journal of Experimental Psychology: Learning, Memory, and Cognition, $27(6), 1411-1423$.

Gordon, P. C., Hendrick, R., \& Levine, W. H. (2002). Memory-load interference in syntactic processing. Psychological Science, 13(5), 425-430.

Greenberg, J. H. (1966). Language universals: with special reference to feature hierarchies (2005reprint ed.). Berlin: Mouton de Gruyter.

Grewendorf, G. (2002). Minimalistische Syntax. Tübingen: Francke.

Haegeman, L. M. V. (1995). Introduction to government and binding theory ( $2^{\text {nd }}$ ed.). Oxford: Blackwell.

Hale, W. G., \& Buck, C. D. (1903). A Latin Grammar (1966reprint ed.). Tuscaloosa, AL: University of Alabama Press.

Hartsuiker, R. J., Antón Méndez, I., \& van Zee, M. (2001). Object Attraction in Subject-Verb Agreement Construction. Journal of Memory and Language, 45, 546-572.

Hartsuiker, R. J., \& Barkhuysen, P. N. (2006). Language production and working memory: The case of subject-verb agreement. Language and Cognitive Processes, 21(1-3), 181204.

Hartsuiker, R. J., Schriefers, H. J., Bock, J. K., \& Kikstra, G. M. (2003). Morphophonological influences on the construction of subject-verb agreement. Memory $\&$ Cognition, $31(8), 1316-1326$.

Haskell, T. R., \& MacDonald, M. C. (2005). Constituent Structure and Linear Order in Language Production: Evidence From Subject-Verb Agreement. Journal of Experimental Psychology: Learning, Memory, and Cognition, 31(5), 891-904.

Haspelmath, M. (2006). Against markedness (and what to replace it with). Journal of Linguistics, 42, 25-70.

Hemforth, B., \& Konieczny, L. (2003). Proximity in agreement errors. In R. Alterman \& D. Kirsh (Eds.), Proceedings of the 25th Annual Meeting of the Cognitive Science Society. Boston, MA: Cognitive Science Society.

Hölscher, C., \& Hemforth, B. (2000). Subject-verb agreement in German. In B. Hemforth \& L. Konieczny (Eds.), German sentence processing (pp. 279-310). Dordrecht: Kluwer.

Jaeger, T. F. (2008). Categorical data analysis: Away from ANOVAs (transformation or not) and towards logit mixed models. Journal of Memory and Language, 59(4), $434-446$.

Jescheniak, J., \& Levelt, W. J. M. (1994). Word Frequency Effects in Speech Production: Retrieval of Syntactic Information and of Phonological Form. Journal of Experimental Psychology: Learning, Memory, and Cognition, 20(4), 824-843.

Jones, D. M. (1993). Objects, streams, and threads of auditory attention. In A. D. Baddeley, D. E. Broadbent, \& L. Weiskrantz (Eds.), Attention: selection, awareness, and control 
(pp. 87-104). Oxford: Oxford University Press.

Jones, D. M., \& Macken, W. J. (1993). Irrelevant Tones produce an Irrelevant Speech Effect: Implications for Phonological Coding in Working Memory. Journal of Experimental Psychology: Learning, Memory, and Cognition, 19(2), 369-381.

Jones, D. M., Madden, C., \& Miles, C. (1992). Privileged Access by Irrelevant Speech to Short-term Memory: The Role of Changing State. The Quarterly Journal of Experimental Psychology, 44A(4), 645-669.

Junqua, J.-C., Fincke, S., \& Field, K. (1999). The Lombard Effect: A Reflex to Better Communicate with Others in Noise. In Proceedings of the 1999 IEEE International Conference on Acoustics, Speech, and Signal Processing (ICASSP) (Vol. 4). Phoenix, AZ: IEEE.

Just, M. A., \& Carpenter, P. A. (1992). A Capacity Theory Of Comprehension - IndividualDifferences In Working Memory. Psychological Review, 99(1), 122-149.

Kemper, S., Herman, R. E., \& Lian, C. H. T. (2003). The costs of doing two things at once for young and older adults: Talking while walking, finger tapping, and ignoring speech or noise. Psychology and Aging, 18(2), 181-192.

Klatte, M., \& Hellbrück, J. (1993). Der "Irrelevant Speech Effect": Wirkungen von Hintergrundschall auf das Arbeitsgedächtnis [The "irrelevant speech effect": Effects of background noise on working memory]. Zeitschrift für Lärmbekämpfung, 40, 91-98.

Klatte, M., Kilcher, H., \& Hellbrück, J. (1995). Wirkungen der zeitlichen Struktur von Hintergrundschall auf das Arbeitsgedächtnis und ihre theoretischen und praktischen Implikationen [Effects of temporal structure of background noise on working memory and their theoretical and practical implications]. Zeitschrift für Experimentelle Psychologie, 42(4), 517-544.

Kostić, A. (1991). Informational approach to the processing of inflected morphology: Standard data reconsidered. Psychological Research, 53, 62-70.

Kostić, A., \& Katz, L. (1987). Processing differences between nouns, adjectives, and verbs. Psychological Research, 49, 229-236.

Levelt, W. J. M. (1983). Monitoring and self-repair in speech. Cognition, 14, 41-104.

Levelt, W. J. M. (1989). Speaking: From intention to articulation. Cambridge, MA: MIT Press.

Levelt, W. J. M., Roelofs, A., \& Meyer, A. S. (1999). A theory of lexical access in speech production. Behavioral and Brain Sciences, 22(1), 1-38.

Lewis, R. L., \& Vasishth, S. (2005). An Activation-Based Model of Sentence Processing as Skilled Memory Retrieval. Cognitive Science, 29, 375-419.

Lewis, R. L., Vasishth, S., \& Van Dyke, J. A. (2006). Computational principles of working memory in sentence comprehension. Trends in Cognitive Sciences, 10(10), 447-454.

Lombard, É. (1911). Le signe de l'elevation de la voix. Annales des Maladies de l'Oreille, du Larynx, du Nez et du Pharynx, 34, 101-119.

Lu, Y. Y., \& Cooke, M. (2008). Speech production modifications produced by competing talkers, babble, and stationary noise. Journal of the Acoustical Society of America, 124 (5), 3261-3275. doi: 10.1121/1.2990705

MacDonald, M. C., \& Christiansen, M. H. (2002). Reassessing working memory: Comment on Just and Carpenter (1992) and Waters and Caplan (1996). Psychological Review, $109(1), 35-54$. 
Macken, W., Tremblay, S., Alford, D., \& Jones, D. (1999). Attentional selectivity in shortterm memory: Similarity of process, not similarity of content, determines disruption. International Journal of Psychology, 34(5-6), 322-327.

Max Planck Institute for Psycholinguistics. (2001). WebCelex. Retrieved March 30 ${ }^{\text {th }}$, 2011, from http://celex.mpi.nl.

McElree, B. (2001). Working Memory and Focal Attention. Journal of Experimental Psychology: Learning, Memory, and Cognition, 27(3), 817-835.

McElree, B., Foraker, S., \& Dyer, L. (2003). Memory structures that subserve sentence comprehension. Journal of Memory and Language, 48, 67-91.

Milin, P., Filipović Djurdjević, D., \& Moscoso Del Prado Martín, F. (2009). The simultaneous effects of inflectional paradigms and classes on lexical recognition: Evidence from Serbian. Journal of Memory and Language, 60(1), 50-64.

Miller, G. A. (1956). The Magical Number Seven, Plus or Minus Two: Some Limits on Our Capacity for Processing Information. Psychological Review, 63, 81-97.

Moravcsik, E. (2006). An Introduction to Syntax - Fundamentals of Syntactic Analysis. London: Continuum.

Müller, S. (2008). Head-Driven Phrase Structure Grammar: Eine Einführung (2 ${ }^{\text {nd }}$ ed.). Tübingen: Stauffenburg.

Nairne, J. S. (1990). A feature model of immediate memory. Memory \& Cognition, 18(3), 251-269.

Oldfield, R. C., \& Wingfield, A. (1965). Response latencies in naming objects. The Quarterly Journal of Experimental Psychology, 17(4), 273-281.

Oomen, C. C. E., \& Postma, A. (2002). Limitations in processing resources and speech monitoring. Language and Cognitive Processes, 17(2), 163-184.

Pearlmutter, N. J., Garnsey, S. M., \& Bock, J. K. (1999). Agreement Processes in Sentence Comprehension. Journal of Memory and Language, 41, 427-456.

Pollard, C., \& Sag, I. A. (1994). Head-driven phrase structure grammar. Chicago, IL: University of Chicago Press.

Poole, G. (2002). Syntactic theory. Basingstoke: Palgrave.

Postma, A., \& Noordanus, C. (1996). Production and detection of speech errors in silent, mouthed, noise-masked, and normal auditory feedback speech. Language and Speech, 39, 375-392.

Potter, M. C. (1984). Rapid Serial Visual Presentation (RSVP): A Method for Studying Language Processing. In D. E. Kieras \& M. A. Just (Eds.), New methods in reading comprehension research (pp. 91-118). Hillsdale, NJ: Erlbaum.

Potter, M. C., \& Lombardi, L. (1998). Syntactic priming in immediate recall of sentences. Journal of Memory and Language, 38(3), 265-282.

Quirk, R., Greenbaum, S., \& Leech, G. N. (1989). A comprehensive grammar of the English language ( $7^{\text {th }}$ ed.). London: Longman.

R Development Core Team. (2010). R: A Language and Environment for Statistical Computing [Computer software manual]. Vienna, Austria. Retrieved from http://www.R-project.org

Radford, A. (2009). Analysing English sentences: a minimalist approach. Cambridge: Cambridge University Press.

Rummer, R., Mohr, G., \& Zimmer, H. (1998). Leistungsbegrenzungen im verbalen Arbeitsgedächtnis: Argumente gegen energetische Ressourcenkonzepte. Kognitions- 
wissenschaft, 7, 134-140.

Sag, I. A., Wasow, T., \& Bender, E. M. (2003). Syntactic theory (2 ${ }^{\text {nd }}$ ed.). Stanford: CSLI Publications.

Salamé, P., \& Baddeley, A. (1982). Disruption of Short-Term Memory by Unattended Speech: Implications for the Structure of Working Memory. Journal of Verbal Learning and Verbal Behavior, 21, 150-164.

Salthouse, T. A. (1988). Resource-Reduction Interpretations Of Cognitive Aging. Developmental Review, 8(3), 238-272.

Schriefers, H., \& van Kampen, A. (1993). Syntaktische Prozesse bei der Sprachproduktion: Zur Numerus-Kongruenz zwischen Subjekt und Verb [Syntactic processes in sentence production: On number agreement between subject and verb]. Sprache $\mathcal{E}$ Kognition, 12(4), 205-216.

Stemberger, J. P. (1984). Structural Errors in Normal and Agrammatic Speech. Cognitive Neuropsychology, 1(4), 281-313.

Stemberger, J. P. (1985). Bound Morpheme Loss Errors in Normal and Agrammatic Speech: One Mechanism or Two? Brain and Language, 25, 246-256.

Thornton, R., \& MacDonald, M. C. (2003). Plausibility and grammatical agreement. Journal of Memory and Language, 48(4), 740-759. doi: 10.1016/S0749-596X(03)00003-2

Uslar, V., Brand, T., Hanke, M., Carroll, R., Ruigendijk, E., Hamann, C., \& Kollmeier, B. (2010). Does sentence complexity interfere with intelligibility in noise? Evaluation of the Oldenburg Linguistically and Audiologically Controlled Sentence Test (OLACS). In Proceedings of the 11th Annual Conference of the International Speech Communication Association INTERSPEECH 2010 (pp. 2482-2485). Makuhari, Japan: International Speech Communication Association.

Van Ewijk, L., \& Avrutin, S. (2010). Article omission in Dutch children with SLI: A processing approach. Entropy, 12, 798-817. doi: 10.3390/e12040798

Vigliocco, G., Butterworth, B., \& Garrett, M. F. (1996). Subject-verb agreement in Spanish and English: Differences in the role of conceptual constraints. Cognition, 61, 261-289.

Vigliocco, G., \& Nicol, J. (1998). Separating hierarchical relations and word order in language production: is proximity concord syntactic or linear? Cognition, 68(1), B13-B29.

Wagener, K. C., Brand, T., \& Kollmeier, B. (2006). The role of silent intervals for sentence intelligibility in fluctuating noise in hearing-impaired listeners. International Journal of Audiology, 45(1), 26-33.

Wagers, M. W., Lau, E. F., \& Phillips, C. (2009). Agreement attraction in comprehension: Representations and processes. Journal of Memory and Language, 61, 206-237.

Waters, G. S., \& Caplan, D. (1996). The capacity theory of sentence comprehension: Critique of Just and Carpenter (1992). Psychological Review, 103(4), 761-772.

Waters, G. S., \& Caplan, D. (2003). The reliability and stability of verbal working memory measures. Behavior Research Methods, Instruments, \& Computers, 35 (4), 550-564.

Wurzel, W. U. (1998). On Markedness. Theoretical Linguistics, 24(1), 53-71. 


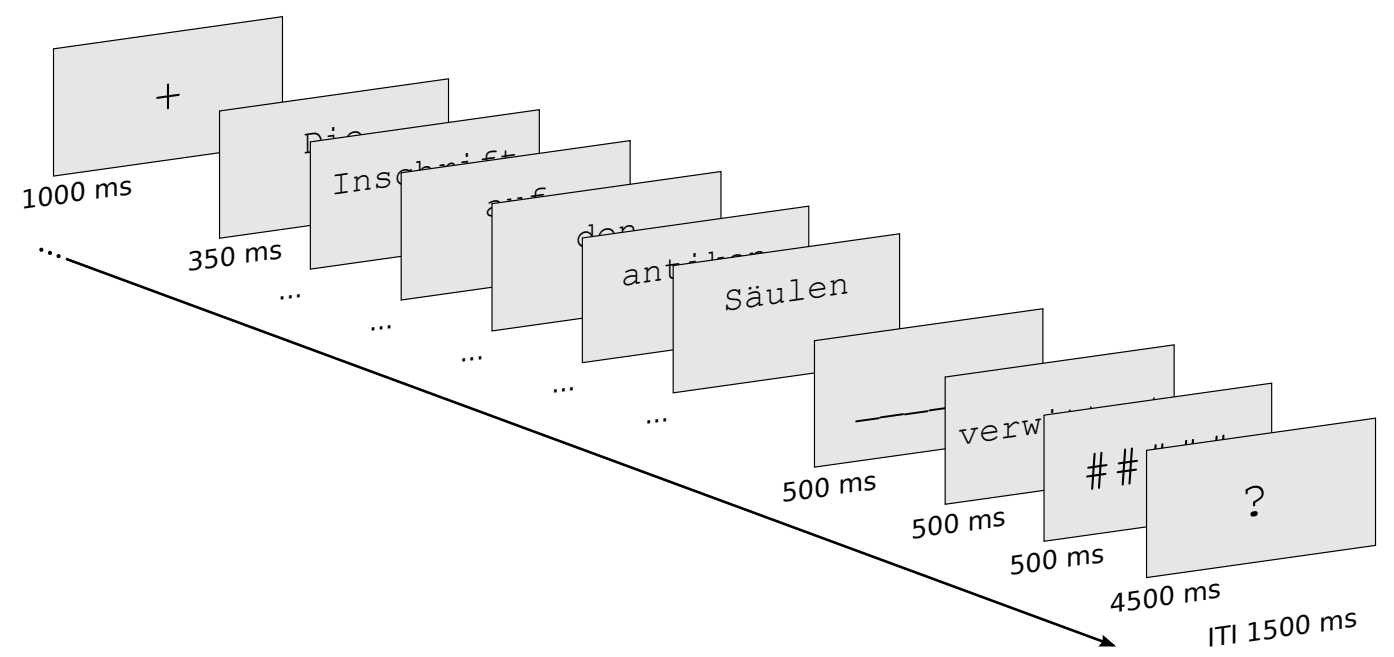

Figure 1: Trial scheme for RSVP stimulus presentation. 
silence

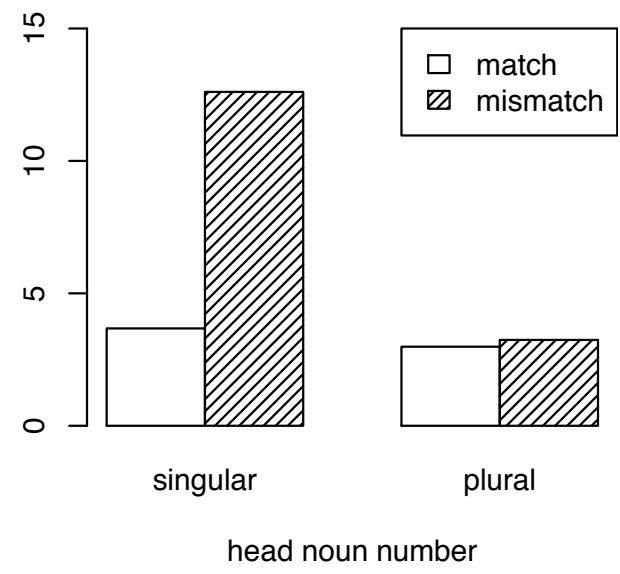

single-talker babble (ICRA 4)

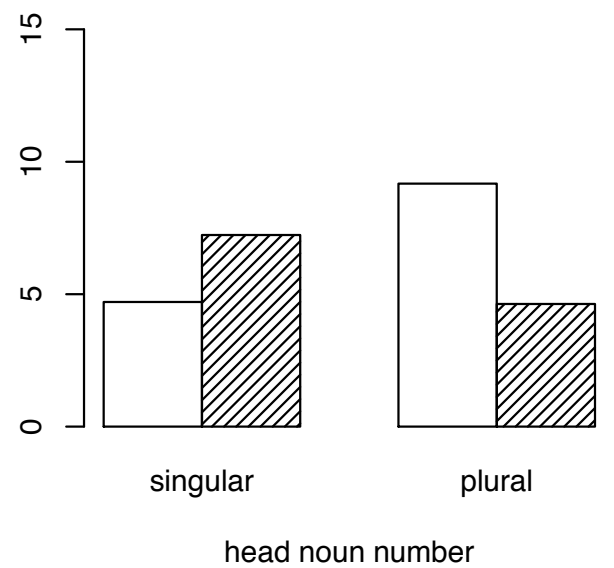

unmodulated noise (ICRA 1)

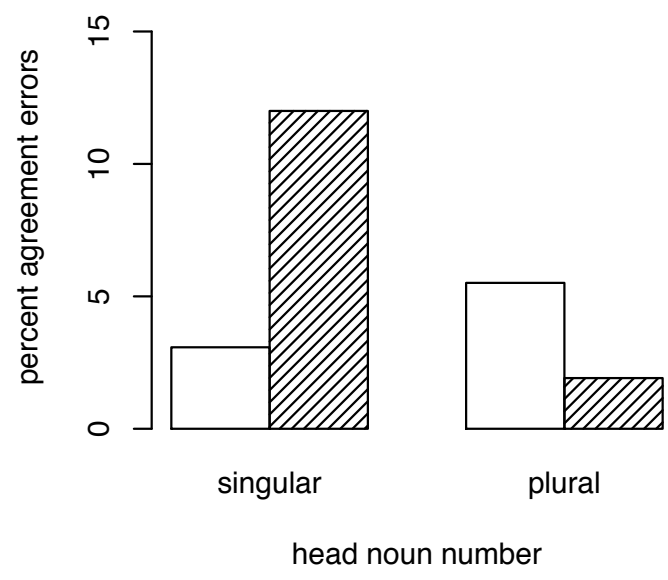

multi-talker babble (ICRA 7)

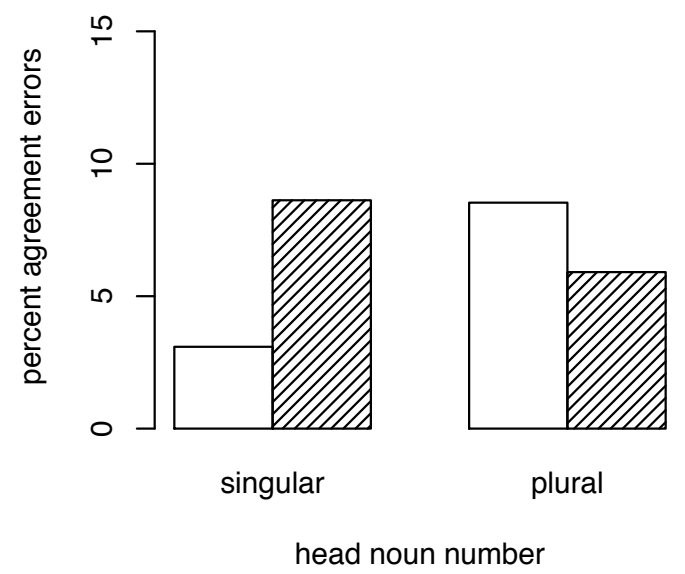

Figure 2: Error percentage under different noise conditions. 
Table 1: Number of sentences produced correctly and with agreement error by number match category (137 answers were classified as other).

\begin{tabular}{llrrll}
\hline Condition & \multicolumn{5}{c}{ Response } \\
\hline Match & Head no. & Total & Corr. & Agreement err. \\
\hline \multirow{2}{*}{ Mismatch } & singular & 930 & 836 & 94 & $(10.1 \%)$ \\
& plural & 861 & 827 & 34 & $(3.9 \%)$ \\
\multirow{3}{*}{ Match } & singular & 1046 & 1008 & 38 & $(3.6 \%)$ \\
& plural & 866 & 809 & 57 & $(6.6 \%)$ \\
\hline
\end{tabular}


Table 2: GLMM coefficients for the agreement error data from the silent baseline condition, predictors are treatment-coded $(N=927$; log-likelihood $=-181.9)$.

\begin{tabular}{lrrrl}
\hline & $\operatorname{Coef} \beta$ & $\mathrm{SE}(\beta)$ & $\mathbf{z}$ & \multicolumn{1}{c}{$\mathbf{p}$} \\
\hline (Intercept) & -3.77 & 0.42 & -9.0 & $<. \mathbf{0 0 0 1}$ \\
Head number:PL & -0.26 & 0.57 & -0.5 & $>0.1$ \\
Match:MISMATCH & 1.46 & 0.42 & 3.5 & $<.001$ \\
Hd no.:PL $\times$ Match:MISMATCH & -1.43 & 0.75 & -1.9 & .055 \\
\hline
\end{tabular}


Table 3: Coefficients for GLM model with noise as factor, predictors are treatment-coded $(N=3703 ;$ log-likelihood $=-761)$.

\begin{tabular}{lrrrl}
\hline & Coef $\beta$ & $\mathrm{SE}(\beta)$ & $\mathbf{z}$ & \multicolumn{1}{c}{$\mathbf{p}$} \\
\hline (Intercept) & -3.80 & 0.37 & -10.2 & $<. \mathbf{0 0 0 1}$ \\
Head number:PL & 0.03 & 0.41 & 0.1 & .952 \\
Match:MISMATCH & 1.50 & 0.37 & 4.1 & $<.0001$ \\
Noise:ICRA1 & 0.11 & 0.42 & 0.3 & .788 \\
Noise:ICRA4 & 0.22 & 0.40 & 0.5 & .588 \\
Noise:ICRA7 & -0.16 & 0.42 & -0.4 & .709 \\
Hd no.:PL $\times$ Match:MISM. & -1.77 & 0.38 & -4.6 & $<.0001$ \\
Hd no.:PL $\times$ Noise:ICRA1 & 0.15 & 0.48 & 0.3 & .752 \\
Hd no.:PL $\times$ Noise:ICRA4 & 1.02 & 0.46 & 2.2 & $<.05$ \\
Hd no.:PL $\times$ Noise:ICRA7 & 1.19 & 0.46 & 2.6 & $<.01$ \\
Match:MISM. $\times$ Noise:ICRA1 & -0.29 & 0.46 & -0.6 & .527 \\
Match:MISM. $\times$ Noise:ICRA4 & -0.89 & 0.44 & -2.0 & $<.05$ \\
Match:MISM. $\times$ Noise:ICRA7 & -0.34 & 0.45 & -0.7 & .456 \\
\hline
\end{tabular}

